possible. Providing a sitter may not always be feasible, especially in light of ongoing novel coronavirus pandemic. ${ }^{6}$

Acknowledgments. None.

Financial support. No financial support was provided relevant to this article.

Conflicts of interest. All authors report no conflicts of interest relevant to this article.

\section{References}

1. Dworkin M, Falkow S, Rosenberg E, Schleifer K, Stackebrandt E. The Prokaryotes. Vol 7. New York, NY: Springer-Verlag; 2007:206-226.
2. Kilic A, Senses Z, Kurekci A, Aydogan H, Basustaoglu A. P592 Nosocomial outbreak of Sphingomonas paucimobilis bacteraemia in an oncology and haematology unit. Int J Antimicrob Agents 2007;29:S137.

3. Toh HS, Tay HT, Kuar WK, Weng TC, Tang HJ, Tan CK. Risk factors associated with Sphingomonas paucimobilis infection. J Microbiol Immunol Infect 2011;44:289-295.

4. Walayat S, Malik A, Hussain N, Lynch T. Sphingomonas paucimobilis presenting as acute phlebitis: a case report. IDCases 2017;11:6-8.

5. Hepatitis A surveillance, July 2020. Florida Department of Health website. http://www.floridahealth.gov/diseases-and-conditions/vaccine-preventabledisease/hepatitis-a/surveillance-data/_documents/2020-july-hep-a-report.pdf. Published August 11, 2020. Accessed August 17, 2020.

6. NHSN frequently asked questions: central line-associated bloodstream infection. Centers for Disease Control and Prevention website. https://www.cdc. gov/nhsn/PDFs/faqs/FAQs-V-6_CLABSI.pdf. Accessed January 14, 2020.

\title{
Antimicrobial stewardship programs and convalescent plasma for COVID-19: A new paradigm for preauthorization?
}

\author{
Michael P. Stevens MD, MPH${ }^{1}$, Payal K. Patel MD, MPH ${ }^{2,3}$ (1) and Priya Nori MD ${ }^{4}$ \\ ${ }^{1}$ Healthcare Infection Prevention Department, Virginia Commonwealth University Health System, Richmond, Virginia, ${ }^{2}$ Infectious Diseases Section, Ann Arbor \\ VA Medical Center, Ann Arbor, Michigan, ${ }^{3}$ University of Michigan, Ann Arbor, Michigan and ${ }^{4}$ Division of Infectious Diseases, Department of Medicine, \\ Montefiore Medical Center, Albert Einstein College of Medicine, Bronx, New York
}

To the Editor-Antimicrobial preauthorization is a core strategy utilized by antimicrobial stewardship programs (ASPs). ${ }^{1}$ ASPs have played an important role in coronavirus disease 2019 (COVID-19) response efforts, including in the preauthorization of novel therapeutic agents such as remdesivir., ${ }^{2,3}$ On August 23, 2020, the US Food \& Drug Administration (FDA) released an emergency use authorization (EUA) for the use of convalescent plasma in treating hospitalized patients with COVID-19. ${ }^{4}$ An important question is what role, if any, ASPs should play in the convalescent plasma distribution process. To our knowledge, ASPs have never been involved in the preauthorization of blood products like convalescent plasma. There are numerous potential advantages and disadvantages to consider regarding ASP involvement in the convalescent plasma preauthorization process (Table 1). The effectiveness of convalescent plasma in the treatment of COVID-19 is still unclear. The data regarding convalescent plasma use are limited. As of June 22, 2020, the Infectious Diseases Society of America (IDSA) COVID-19 treatment guidelines recommend the use of convalescent plasma only in the context of a clinical trial. ${ }^{5}$ Importantly, enrollment in existing trials has been potentially compromised by the EUA announcement. Major scientific organizations will likely continue to support guidelines emphasizing convalescent plasma use only in the context of clinical trials. It is also possible that additional study data will become

\footnotetext{
Author for correspondence: Michael P. Stevens, E-mail: michael.stevens@vcuhealth. org

Cite this article: Stevens MP, Patel PK, and Nori P. (2021). Antimicrobial stewardship programs and convalescent plasma for COVID-19: A new paradigm for preauthorization?. Infection Control \& Hospital Epidemiology, 42: 1153-1154, https://doi.org/10.1017/ ice. 2020.459
}

available that will influence convalescent plasma use. This uncertainty about the optimal role of convalescent plasma supports the use of preauthorization to allow for real-time adjustment of convalescent plasma use in a controlled, optimized fashion.

Many ASPs have been responsible for the creation and maintenance of COVID-19 treatment guidelines and are ideally situated to inform frontline clinicians about the optimal use of convalescent plasma relative to other therapies. Preauthorization, coupled with local treatment guidelines, would enhance the optimal use of convalescent plasma. Additionally, the new convalescent plasma EUA may increase demand for convalescent plasma use, resulting in timely access issues. A preauthorization process utilizing the best available evidence would facilitate providing convalescent plasma to patients who may benefit.

Health systems would benefit tremendously from ASP involvement in the COVID-19 convalescent plasma distribution process. ASPs can provide guidance for incorporation of convalescent plasma into local treatment guidelines, can provide insight and guidance based on their experiences with other COVID-19 focused EUAs (including hydroxychloroquine, now revoked ${ }^{6}$, and remdesivir ${ }^{7}$ ), and can help develop processes for convalescent plasma eligibility screening and preauthorization. If health systems do not adopt preauthorization for convalescent plasma, we recommend that use be carefully monitored to ensure that this resource is being used optimally. ASPs have proven integral in COVID-19 response efforts-investing in and scaling up ASP resources will assist health systems adapt and respond to evolving pandemic challenges.

Financial support. No financial support was provided relevant to this article. Conflicts of interest. All authors report no conflicts of interest relevant to this article.

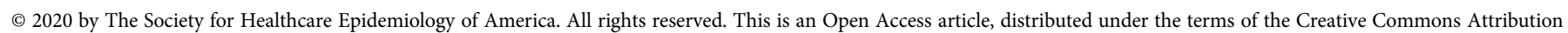

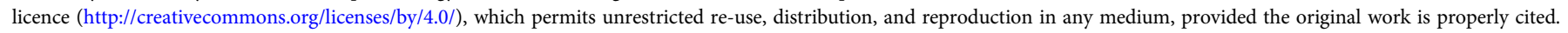


Table 1. Considerations For and Against Antimicrobial Stewardship Program (ASP) Involvement in COVID-19 Convalescent Plasma Preauthorization

\begin{tabular}{|c|c|}
\hline For ASP Involvement & Against ASP Involvement \\
\hline $\begin{array}{l}\text { - ASPs already have } \\
\text { preauthorization infrastructure in } \\
\text { place } \\
\text { - Transfusion medicine programs } \\
\text { likely would need to create pre- } \\
\text { authorization processes de novo } \\
\text { and identify how to staff these } \\
\text { - ASP personnel are experts at } \\
\text { creating and applying algorithm- } \\
\text { based preauthorization criteria } \\
\text { - ASPs that are already responsible } \\
\text { for local covID-19 guidelines can } \\
\text { help contextualize convalescent } \\
\text { plasma use relative to other } \\
\text { potential therapies } \\
\text { - ASP personnel are experts at } \\
\text { cooperative integration with non- } \\
\text { infectious diseases or non- } \\
\text { pharmacy-based service lines }\end{array}$ & $\begin{array}{l}\text { - ASPs have no direct involvement } \\
\text { with transfusion medicine } \\
\text { programs or authority to restrict } \\
\text { access to blood products } \\
\text { - ASP personnel are not experts in } \\
\text { transfusion medicine } \\
\text { - ASP involvement will divert time } \\
\text { away from other important } \\
\text { stewardship activities, such as } \\
\text { antibiotic use monitoring } \\
\text { - ASPs are put in the difficult } \\
\text { position of brokering } \\
\text { convalescent plasma access } \\
\text { against scientific community } \\
\text { recommendations to use only in } \\
\text { the context of randomized, } \\
\text { clinical trials }\end{array}$ \\
\hline
\end{tabular}

\section{References}

1. Dellit TH, Owens RC, McGowan JE, et al. Infectious Diseases Society of America and the Society for Healthcare Epidemiology of America guidelines for developing an institutional program to enhance antimicrobial stewardship. Clin Infect Dis 2007;44:159-177.

2. Stevens MP, Patel PK, Nori P. Involving antimicrobial stewardship programs in COVID-19 response efforts: all hands on deck. Infect Control Hosp Epidemiol 2020;41:744-745.

3. Mazdeyasna $\mathrm{H}$, Nori $\mathrm{P}$, Patel $\mathrm{P}$, et al. Antimicrobial stewardship at the core of COVID-19 response efforts: implications for sustaining and building programs. Curr Infect Dis Rep 2020;22:23.

4. US Food \& Drug Administration website. https://www.fda.gov/media/ 141477/download. Accessed August 25, 2020.

5. Bhimraj A, Morgan RL, Shumaker AH, et al. Infectious Diseases Society of America guidelines on the treatment and management of patients with COVID-19. Infectious Diseases Society of America website. https://www. idsociety.org/practice-guideline/covid-19-guideline-treatment-andmanagement/. Accessed August 25, 2020.

6. FDA news release. Coronavirus (COVID-19) update: FDA revokes emergency use authorization for chloroquine and hydroxychloroquine. US Food \& Drug Administration website. https://www.fda.gov/news-events/ press-announcements/coronavirus-covid-19-update-fda-revokes-emergencyuse-authorization-chloroquine-and. Accessed August 25, 2020.

7. FDA news release. Coronavirus (COVID-19) update: FDA issues emergency use authorization for possible COVID-19 treatment. US Food \& Drug Administration website. https://www.fda.gov/news-events/press announcements/coronavirus-covid-19-update-fda-issues-emergencyuse-authorization-potential-covid-19-treatment. Accessed August 25, 2020

\section{Regarding data visualization}

\section{David Birnbaum PhD, MPH (1)}

Applied Epidemiology, Sidney British Columbia, School of Population \& Public Health, University of British Columbia, Vancouver, British Columbia, Canada and School of Health Information Science, University of Victoria, Victoria, British Columbia, Canada

To the Editor-The review by Salinas et $\mathrm{al}^{1}$ introduces many important aspects concerning the science of data visualization. However, the references cited in support of an assertion that the best ways to visualize data remain unclear overlooks several important resources that provide insightful practical advice on optimal choices. In particular, the work of William Cleveland, whose career was devoted to scientific study of visual encoding and decoding of scientific data, and the work of various cognitive psychologists are noteworthy. Cleveland's findings are distilled into 2 very useful books that have been reviewed in this journal. ${ }^{2,3}$ Important findings from cognitive psychology articles are distilled into various comprehensive review publications, like that of Gigerenzer et al. ${ }^{4}$ The graph examples illustrated by Salinas et al should be viewed with key concepts from Cleveland and Gigerenzer in mind. Exploratory data analysis methodology based on data visualization principles and techniques established in the 1970s-1990s “... add an exciting and useful tool to the epidemiologist's repertoire." 5 The works of Cleveland, Gigerenzer, and others were paramount in informing many of the choices I had to make (and defend against those who initially found them unfamiliar) throughout my career in hospital and

Author for correspondence: David Birnbaum, E-mail: david.birnbaum@ubc.ca Cite this article: Birnbaum D. (2021). Regarding data visualization. Infection Control \& Hospital Epidemiology, 42: 1154-1155, https://doi.org/10.1017/ice.2020.457 public health agency projects related to recognizing the onset of adverse trends efficiently and informing a wide range of audiences about comparisons of healthcare-associated infection rates. ${ }^{6-9}$

\section{Acknowledgments.}

Financial support. No financial support was provided relevant to this article.

Conflicts of interest. The author reports no conflicts of interest relevant to this article.

\section{References}

1. Salinas JL, Kritzman J, Kobayashi T, et al. A primer on data visualization in infection prevention and antimicrobial stewardship. Infect Control Hosp Epidemiol 2020;41:948-957.

2. Birnbaum D. Book review, re: Cleveland WS, Visualizing Data. Infect Control Hosp Epidemol 1994;15:763.

3. Birnbaum D. Book review, re: Cleveland WS, The Elements of Graphing Data. Infect Control Hosp Epidemiol 1996;17:706.

4. Gigerenzer G, Gaissmaier W, Kurz-Milcke E, Schwartz LM, Woloshin S. Helping doctors and patients make sense of health statistics. Psychol Sci Public Interest 2007;8:53-96.

5. Shelly MA. Exploratory data analysis: data visualization or torture? Infect Control Hosp Epidemiol 1996;17:605-612.

(C) 2020 by The Society for Healthcare Epidemiology of America. All rights reserved. This is an Open Access article, distributed under the terms of the Creative Commons Attribution licence (http://creativecommons.org/licenses/by/4.0/), which permits unrestricted re-use, distribution, and reproduction in any medium, provided the original work is properly cited. 